\title{
Research on the Training System of Innovative Talents for Cost Engineering Professional
}

\author{
Qian LI \\ College of Civil Engineering and Mechanics, Central South University of Forestry and Technology, \\ Changsha 410004, China \\ semese_li@163.com
}

Keywords: Innovative Talents, Training System, Cost Engineering Professional.

\begin{abstract}
This paper discusses the innovative education reform of cost engineering professional: 1) transform education idea, update education concept, 2) explore the new personnel training mode, we will construct the innovative education system based on market demand-oriented, in order to widen specialty specification and improve the innovation ability as the goal, 3) cultivating innovative talents in innovative activities, improve the innovation ability should not only rely on study the innovative educational theory courses but also need some innovative activities support, which enable students to cultivate ability from the competition, to improve in the scientific practice, to grow thought participate in the social and cultural activities. This paper forms an innovative training objective of market-oriented, a curriculum system in order to improve the innovation ability and broaden the professional caliber for the purpose, a practical teaching system based on engineering ability, innovation ability training as the goal. Finally, get the innovative training system of engineering cost "wide caliber, thick foundation, practical, heavy innovation".
\end{abstract}

\section{Introduction}

The rapid development of construction industry has driven the development of engineering cost industry, but if the engineering cost industry would have sustained and rapid development the core and foundation is enhancing engineering cost personnel's comprehensive quality. It is imminent to strengthen industry building and engineering cost professional's cultivation, to improve the ability of engineering cost management [1]. In order to cultivate innovative talents of high quality project cost of economic construction and social development needs. We must be based upon economy, relied on industry development, aimed at the requirement of talent's knowledge structure and ability requirement in the knowledge economy era, optimized curriculum, reformed personnel training mode, improved the quality of personnel training, enhanced their ability to innovate and social adaptability, and made them actively for engineering frontline service.

Engineering cost specialty at this stage need to cultivate the talents of innovative consciousness and ability. But the traditional personnel training system have been unsuited to cultivate innovative talents, and now faced the reforming and perfecting task. Personnel training system is overall design blueprint and implementation plan of personnel training. The construction and optimization of personnel training system need to solve two problems: one is to cultivate what kind of people that is the problem of training target; another is to rely on what training that are the problems of curriculum system, practice teaching system and teaching mode.

\section{Innovative education reform of engineering cost}

\section{Transform educational idea, update education concepts}

Establish a correct view of students. Teachers should recognize that each student has innovative potential and independent personality, and that respecting the student's personality is the precondition to cultivate the innovation spirit [2]. 
Learn main, teach secondary. That is teachers should provide active and lively development space for students in the knowledge imparting process to avoid cramming indoctrination. In a certain sense, active learning is the foundation of creative thinking.

Foster problem consciousness. The traditional teaching modes focus on cultivating students' ability to analyze and solve problems, while ignoring their problem consciousness and query ability. Students' curiosity is suppressed by the traditional teaching mode. At present, one of main tasks is to release this "nature"[3]. Einstein once said "posing problem is more important than solving a problem, because to present a valuable problem may open up a new field, but to solve the problem just need some skills". Therefore, if we will cultivate innovative talents, we should attach great importance to cultivating students' problem consciousness.

Pay attention to practice teaching. Genuine knowledge comes from practice, and practice is a source of innovation. Practical teaching can provide students an important way to turn theoretical knowledge into the ability [4]. According to the present situation of heavy theory and light practice, through simplified theoretical teaching content, compressed theory teaching time, improved the practical teaching status, it could train students' innovation consciousness and ability in practice.

\section{Explore new training mode}

To explore the new training mode is an important link of the cultivating innovative talents. We will construct the innovative education system based on market demand-oriented, in order to widen specialty specification and improve the innovation ability as the goal. It mainly focuses on the reform of the curriculum system, teaching content, methods and means.

Reform the curriculum system and teaching content. Set curriculum system, on the one hand to strengthen basic curriculum education, on the other hand to implement interdisciplinary education, increase the proportion of elective courses, and broaden the professional caliber. In order to improve the students' innovation ability, offering innovation education curriculum, teaching basic knowledge and creation techniques of creative research, training creative thinking, etc.

Reform teaching method and means. Actively promote heuristic, discussion and research teaching methods; use multimedia, video technology and network technology into the teaching methods; strive to impart more knowledge in limited time.

\section{Cultivate innovative talents though innovation activities}

The raise of innovation ability should not only to rely on study theory courses of innovative educational, but also need to be supported by a number of innovative activities, which enable students to cultivate ability from the competition, to improve in the scientific practice, to grow thought participate in the social and cultural activities.

Cultivate ability from the competition. Encourage, motivate students to actively participate in various competitions, so that students are aware of the fun of specialty. The academic and interest into a whole, is an effective way to improve students' innovation ability. Actively organized competition activities also can strengthen exchanges and cooperation between the various departments and various universities, and achieve common progress.

Improve in the scientific practice. The scientific practice is something investigation, experiment and other activities which use certain means and methods to understanding the inherent nature and laws of certain things. The teacher shows their research achievements in the classroom and tells about research experiences, which activate students' creative thinking, enable students to be inspired and study the valuable research topics. Practice is the best teacher, emphasized the research platform for the teaching service. Let the students participate in the teachers' research that is the best way to improve the students' ability of scientific research and practice.

Grow thought participate in the social and cultural activities. Social practice includes social survey, productive labor, voluntary service, public welfare activities, technological invention and work-study etc. The education Ministry requires each student participated in one social survey at least and write a report during the university. 


\section{Build training system}

\section{Training target}

This paper forms an innovative training target of market-oriented: that is to cultivate innovative talents with engineering ability, which face the need of national construction in the future, adapt science and technology development to the future, develop all-round, has the basic theory of economics, management science, engineering technology and the laws, regulations and other knowledge, master engineering economy, modern management theory, engineering technique, construction law and construction market rules, obtain basic training of cost engineer, engage in engineering measurement and valuation and manage the whole process in the field of domestic and international engineering construction.

\section{Training system}

This paper forms a curriculum system in order to improve the innovation ability and broaden the professional caliber for the purpose; a practical teaching system based on engineering ability, innovation ability training as the goal. Finally, get the innovative training system of engineering cost "wide caliber, thick foundation, practical, heavy innovation". This paper show the training system though figure 1 and figure 2 .

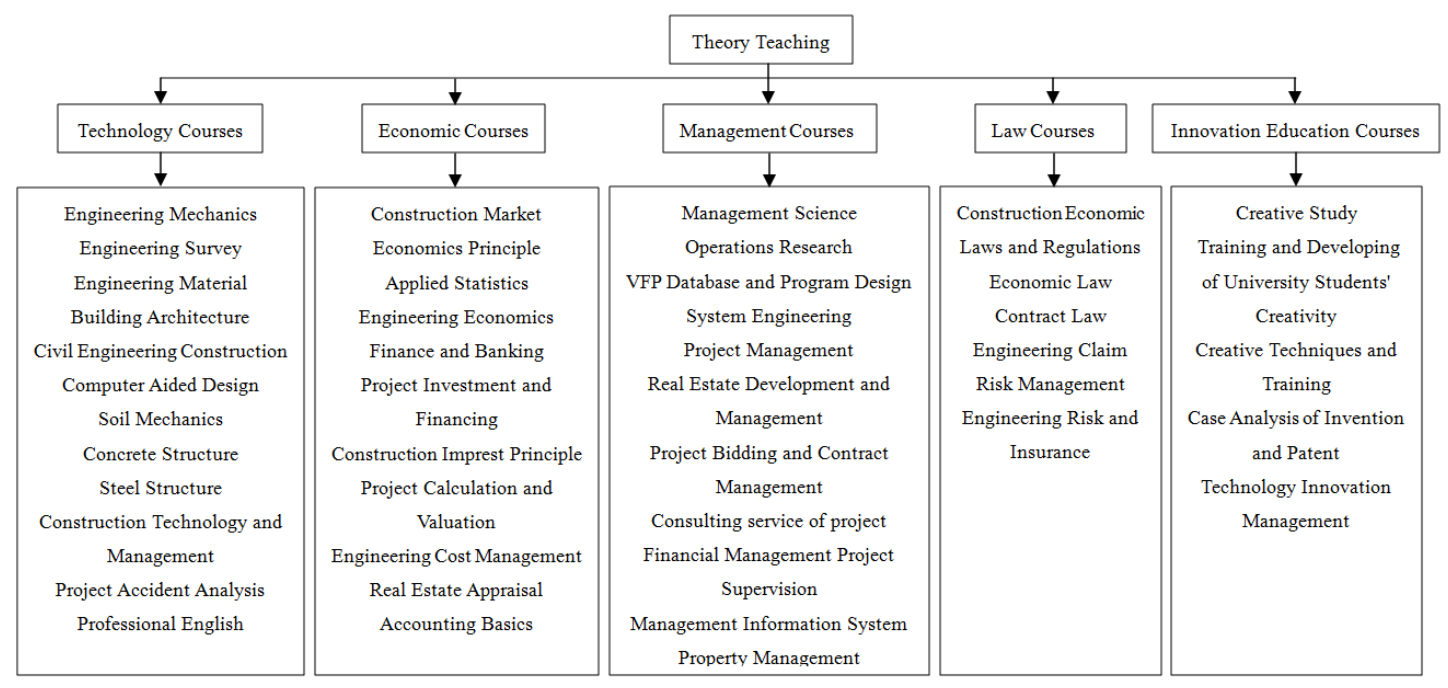

Figure.1 Theory Teaching of Creative Personal Training System

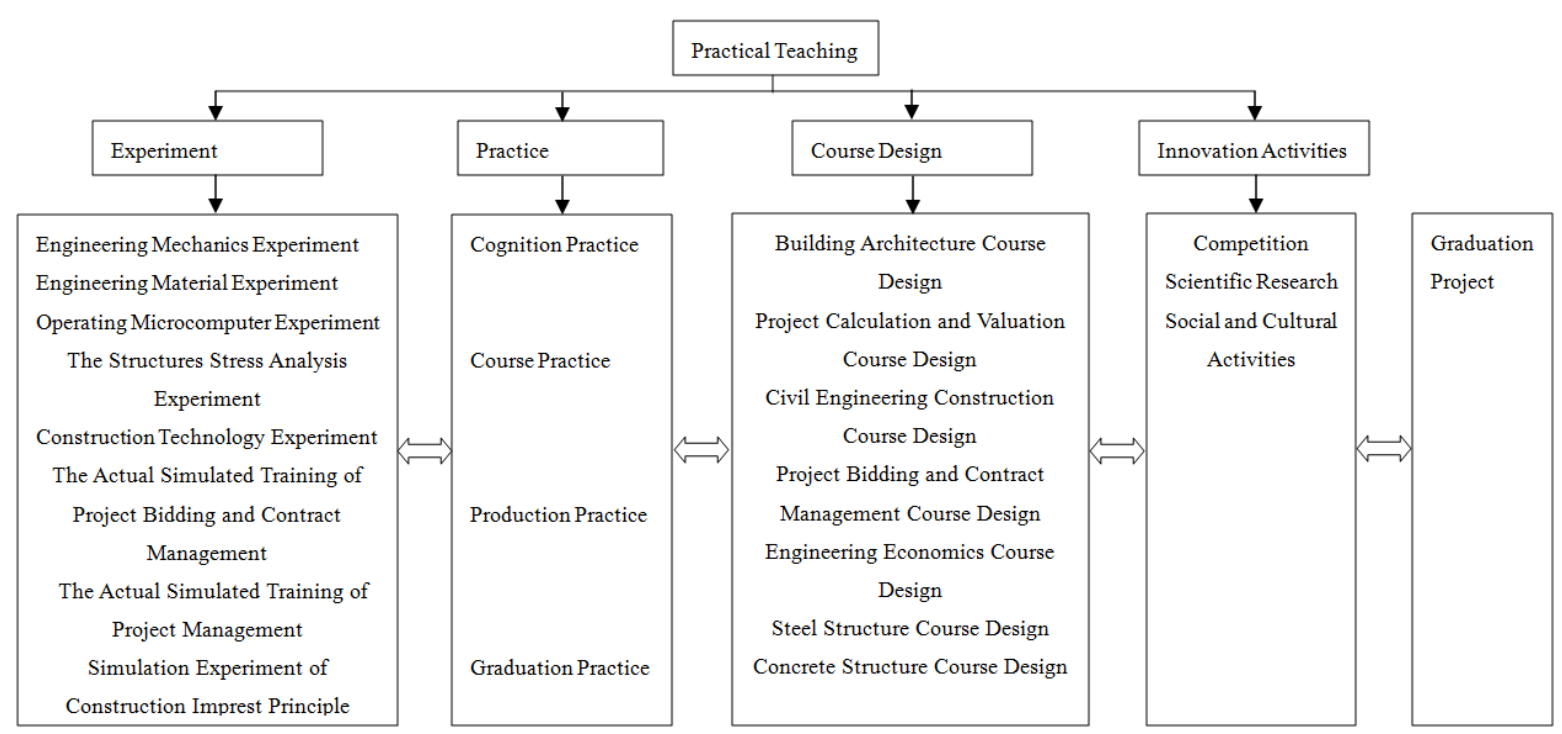

Figure.2 Practical Teaching of Creative Personal Training System 


\section{Summary}

This paper discusses the innovative education reform of cost engineering professional. It forms an innovative training objective of market-oriented, a curriculum system in order to improve the innovation ability and broaden the professional caliber for the purpose, a practical teaching system based on engineering ability, innovation ability training as the goal. Finally, get the innovative training system of engineering cost "wide caliber, thick foundation, practical, heavy innovation".

\section{Acknowledgement}

This research was financially supported by the College Teaching Reform Project in Central South University of Forestry and Technology Science.

\section{References}

[1] Yilin Ying, Lin Yan, Introduction to Engineering Cost, China Communications Press, Bei Jing, 2009.

[2] Wenzhong Qin, Hanming Xu, Ruijie Wang, Bingjian Hou: submitted to Journal of Architectural Education in Insitutions of Higher Learning (2004).

[3] Hui Jiang, Huiguang Yin, Yang Wang: submitted to Journal of Xuzhou Institute of Technology (2006).

[4] Jie Li, Yuanfang Liu: submitted to Journal of Fujian University of Technology (2009). 